\title{
Reactivating tammar wallaby blastocysts oxidize fatty acids and amino acids
}

\author{
R. E. Spindler ${ }^{1 *}$, M. B. Renfree ${ }^{1}$, G. Shaw ${ }^{1}$ and D. K. Gardner ${ }^{2+}$ \\ 'Dept of Zoology, University of Melbourne, Parkville, 3051, Australia; and ${ }^{2}$ Institute of Reproduction and Development, \\ Monash University, Clayton 3168, Australia
}

\begin{abstract}
The tammar wallaby, Macropus eugenii, has a ruminant-like digestive system which may make a significant concentration of amino acids and fatty acids available to the blastocyst via uterine fluids. Fluorescent and radioisotope analyses were performed to determine the rate of glutamine and palmitate use by blastocysts recovered on day 0,3 , 4,5 and 10 after reactivation induced by removal of pouch young (RPY). Between day 0 and 4 glutamine uptake increased from $15.6 \pm 6.6$ to $36.1 \pm 2.7$ pmol per embryo $\mathrm{h}^{-1}(P<$ 0.01 ) and ammonium production increased from $8.2 \pm 4.3$ to $26.6 \pm 3.0 \mathrm{pmol}$ per embryo $\mathrm{h}^{-1}(P<0.01)$. Glutamine oxidation did not increase until day 10 after RPY $(P<$ 0.01 ), but the percentage of glutamine oxidized increased from $4.5 \pm 3.1 \%$ during diapause to $31.2 \pm 12.6 \%(P<0.01)$ by day 5 after RPY and increased further to $51.0 \pm$ $15.8 \%(P<0.01)$ by day 10 after RPY. Palmitate oxidation also increased from $0.3 \pm 0.1$ by day 0 blastocysts to $3.8 \pm 1.7$ pmol per embryo $h^{-1}(P<0.01)$ by day 4 blastocysts. This increase provides a greater potential for ATP production, possibly to supply increased demand due to the coincident resumption of mitoses. The ATP:ADP ratio within blastocysts had reduced by the time of the first measurement at day $3(0.5 \pm 0.2$ pmol per embryo $\left.h^{-1} ; P<0.01\right)$ compared with day 0 blastocysts $(1.4 \pm 0.3$ pmol per embryo $\mathrm{h}^{-1}$ ). It is likely that metabolism of amino acids and fatty acids contributes to the energy supply during reactivation of tammar wallaby blastocysts after embryonic diapause.
\end{abstract}

\section{Introduction}

The tammar wallaby (Macropus eugenii) is one of many mammals that have embryonic diapause (Renfree and Calaby, 1981). In tammars, diapause is controlled by the sucking stimulus of the pouch young from the previous birth. During the first 10 days after removal of pouch young (RPY) there is a 45-fold increase in volume of the blastocoel (Tyndale-Biscoe and Renfree, 1987). However, this is nearly a week after initial signs of blastocyst reactivation such as resumption of mitosis (day 4; Berger, 1970), progesterone pulse associated with pregnancy maintenance (day 5; Fletcher et. al. 1988), and the time of irreversible blastocyst reactivation (day 3; Gordon et al., 1988). Blastocyst glucose metabolism has been shown to change at about day 5 after RPY, while endometrial metabolism is not significantly different from quiescent tissues until 10 days after RPY (Spindler et. al., 1998). The metabolism of these maternal tissues did not provide additional answers to the timing of reactivation of the tammar reproductive system as significant

*Correspondence address: Conservation and Research Centre,

1500 Remount Rd, Front Royal VA 22630, USA

tPresent address: Centre for Reproductive Medicine, 799 East Hampden Ave., Suite 300 Englewood, CO 80110, USA.

Revised manuscript received 18 August 1998. changes were not detected until after changes in blastocyst activity. However, endometrial metabolism was significantly related to metabolic activity of the blastocyst, and is essential for recognizing blastocysts recovered from animals of advanced or delayed reactivation (Spindler et al., 1998).

Therefore, current information on blastocyst metabolism indicates that metabolic reactivation takes place immediately after, or around the time of, mitosis resumption. However, it is possible that glucose may not be the preferred substrate of the tammar blastocyst and that examination of other energy substrates may indicate a different time for metabolic reactivation, as there is little other information on metabolism of tammar embryos. Other embryos that undergo extensive expansion, such as those of rabbits, cows and horses, appear to have a high oxidative capacity (Fridhandler, 1961; Biggers and Stern, 1973; Benos and Balaban, 1980; Pike, 1981; Rieger et al., 1987; Wales and Du, 1994). Blastocysts of monogastric animals, such as rabbits and horses, oxidize glucose (Fridhandler, 1961; Rieger et al., 1987) but the embryos of ruminant mammals like sheep and cattle have limited capacity to oxidize glucose (Thompson et al., 1991; Rieger et al., 1992a; Gardner et al., 1993). These embryos may therefore oxidize energy sources other than, or in addition to, carbohydrates (Rieger and Guay, 1988; Gardner et al., 1993). 
The digestion of cellulose by rumination results in higher concentrations of amino and fatty acids in maternal circulation compared with those of non-ruminants. The anatomy of the macropodid digestive system is similar to that of ruminants, particularly in the complexity of the stomach and the simplicity of caecum and colon (Home, 1814; Owen, 1834). Macropodids also have a 'ruminant-like' digestive physiology (Waring et al., 1966; Hume, 1982). In one macropodid, the quokka (Setonix brachyurus), the microorganisms that participate in cellulose digestion produce volatile fatty acids that are similar to those in sheep and cows (Moir et al., 1956). Foregut fermenters such as kangaroos, wallabies and true ruminants have 'nutrient advantages' in that food can be regurgitated and remasticated (Hume, 1982). Fermentation products (fatty acids, ammonium and gases) pass through the entire gut for further absorption and digestion, and urea nitrogen can be recycled rather than lost by excretion. The tammar has the ruminant-like strategy of urea cycling (Kinnear and Main, 1975). Another kangaroo, Macropus robustus, can digest nitrogen to a level comparable with sheep, cattle and rabbits (Brown, 1959). Both strategies allow the production of amino acids, independent of the nutrient value of their food. The yolk sac fluid of tammar embryos and fetuses contains amino acids in greater concentrations than in maternal sera, indicating selective transfer of amino acids through the yolksac placenta (Renfree, 1970; 1973). The ruminant-like digestive physiology of the tammar may increase the availability of amino acids and lipids in maternal sera and uterine secretions for use by the embryos as energy substrates.

The amino acid glutamine has been extensively studied because it can be used as an energy substrate (Rieger et al., $1992 \mathrm{a}, \mathrm{b}$ ), a chelator (Deighton and Hider, 1989), an organic osmolyte (Chatot et al., 1990; Lawitts and Biggers, 1992, Biggers et al., 1993), or a protein and nucleic acid precursor, and possibly a buffer against changes in intracellular $\mathrm{pH}$ (Bavister and McKiernan, 1993). Glutamine is taken up and used as an energy source by mouse, pig, sheep, cattle and hamster embryos (Rieger and Guay, 1988; Gardner et al., 1989; Chatot et al., 1990; Petters et al., 1990; McKiernan et al., 1991; Tiffin, et al., 1991, Lewis and Kaye, 1992; Rieger, 1992; Bavister and McKiernan, 1993; Hewitson, 1993; Du and Wales, 1993; Wales and Du, 1994; Jamshidi and Kaye, 1995). Glutamine also enhances development of both hamster (Carney and Bavister, 1987) and mouse embryos in vitro (Chatot et al., 1989; Biggers et al., 1993).

Fatty acids produced by fermentation supply most of the energy requirements of ruminants (Annison and Armstrong, 1970). Fatty acids are also incorporated into membranes as phospholipids and glycolipids but the need for oxidizable fatty acids by functioning cells is thought to impose the greatest demand on fatty acid transport systems (Fredrickson and Gordon, 1958). Palmitic, stearic, oleic and linoleic acids together make up $80 \%$ of circulating free fatty acids, while short chain fatty acids make up only $10 \%$. The rate of removal of palmitate from the bloodstream of dogs and rabbits suggests that this fatty acid is supplied to most tissues of the body (Bierman et al., 1957).

Although there is no direct evidence for the availability of fatty and amino acids in the uterus, fatty acid content rises as bovine blastocyst weight or volume increases, indicating that fatty acid uptake in embryos may be related to these parameters of embryo development (Betteridge et al., 1980; Menezo et al., 1982). In addition, the inhibition of fatty acid metabolism has a profound influence on the developmental capacity and number of inner cell mass and trophectoderm cells of mouse embryos (Hewitson et al., 1996). Palmitic acid is present in day $7-14$ cattle embryos and a high content of fatty acids, particularly palmitic and oleic acids, is also detected in the pig oocyte (Menezo et al., 1982; Homa et al., 1986). The long chain fatty acid palmitate is taken up by mouse cleavage stage embryos but it inhibits development at this stage (Quinn and Whittingham, 1982; Nonogaki et al., 1994). Although rates of oxidation of acetate are low (Waugh and Wales, 1993), palmitate, stearate, oleate and propionate will support rabbit embryos from the zygote to viable morula (Kane, 1979). Palmitate is incorporated into embryo lipids and used as an energy source by mouse embryos with more than 8 cells, although the quantity metabolized is low (Flynn and Hillman, 1980). Furthermore, palmitate and oleic acid together promote mouse blastocyst hatching when added at the blastocyst stage (Quinn and Whittingham, 1982). The apparently contradictory results from mouse embryos highlight the different requirements and therefore different capacities to metabolize substrates of embryos at different stages. Although there is no direct evidence that palmitate is present in uterine fluids, it is likely that palmitate is available, is used and may even be required by blastocysts during cavity expansion.

The increased concentrations of circulating amino and fatty acids in the ruminant-like marsupials may be reflected in the use of these substrates as energy sources by their developing embryos. This study investigated the role of the amino acid glutamine and the fatty acid palmitate as energy sources in the blastocyst of the tammar wallaby during diapause and subsequent reactivation.

\section{Materials and Methods}

\section{Animals}

Tammar wallabies from Kangaroo Island, South Australia, were maintained in a breeding colony at Monash University, Clayton in open grassy yards. A diet of pasture grasses was supplemented with oats, lucerne hay, fresh vegetables and water ad libitum. Care and treatment of the animals conformed to the National Health and Medical Research Council of Australia guidelines (1990) and all experiments were approved by Institution Animal Experimentation Ethics Committees.

\section{Embryo recovery}

Females carrying a pouch young older than 10 days were assumed to have a diapausing blastocyst in utero which will reactivate if the sucking pouch young is removed (RPY) during the breeding season which is between February and 
May. A total of 50 blastocysts were recovered from 58 females. Females were killed by cervical dislocation, and blastocysts flushed immediately post mortem from the uterus using $2 \mathrm{ml}$ of phosphate buffered saline at $37^{\circ} \mathrm{C}$ supplemented with $1 \mathrm{mmol}$ glutamine $\mathrm{l}^{-1}, 1 \mathrm{mmol}$ palmitate $\mathrm{l}^{-1}$ as sole substrates and $2 \mathrm{mg} \mathrm{BSA} \mathrm{ml}^{-1}$ (Bayer Diagnostics, Melbourne) at days $0,3,4,5,6$ and 10 after RPY. The medium containing embryos was maintained at $37^{\circ} \mathrm{C}$ throughout handling, and embryos were transferred using pulled glass pipettes the internal diameter of which was only slightly larger than the blastocyst. The diameter of each tammar trophoblast was measured with an eyepiece graticule, calibrated with a slide micrometer and the surface area calculated using the formula for surface area of a sphere. Glutamine and palmitate metabolism by one group of blastocysts (days $0,3,4,5,10$ ) was then analysed using a combination of fluorescent (glutamine) and radio-isotope (glutamine and palmitate) techniques, while the number of cells was determined using the remaining blastocysts (days $0,3,4,5,6,10$ ).

\section{Analysis of metabolism and adenine nucleotide ratios}

Embryos $(n=26)$ were individually transferred through several drops of incubation media with $1.0 \mathrm{mmol}$ glutamine $1^{-1}$ and $1.0 \mathrm{mmol}$ palmitate $1^{-1}$, and finally transferred to incubation media with a proportion of unlabelled and $\mathrm{L}-\left[{ }^{3} \mathrm{H}\right]-$ labelled glutamine $\quad\left(0.001 \mathrm{mmol}^{-1} ; \quad 0.05 \mathrm{mCi} \mathrm{ml}^{-1}\right.$; Amersham, Sydney) and unlabelled and U-[ $\left[{ }^{14} \mathrm{C}\right]$-palmitate $\left(0.1 \mathrm{mmol} \mathrm{l}^{-1} ; 0.082 \mathrm{mCi} \mathrm{ml}^{-1}\right.$; Amersham) equalling a total of $1.0 \mathrm{mmol} \mathrm{l}^{-1}$ of each substrate. These blastocysts were then transferred with $5 \mu \mathrm{l}$ of this medium to the lid of a $1.5 \mathrm{ml}$ Eppendorf centrifuge tube. The base of the centrifuge tube contained $1.5 \mathrm{ml}$ of $25 \mathrm{mmol} \mathrm{NaHCO}_{3} \mathrm{l}^{-1}$, acting as a trap for the evolved ${ }^{14} \mathrm{CO}_{2}$ and ${ }^{3} \mathrm{H}_{2} \mathrm{O}$. Three tubes contained only the trap and incubation media - no embryo was present (blank). Three tubes contain the trap and incubation media mixed together (total label present). After $3 \mathrm{~h}, 1 \mathrm{ml}$ of the $\mathrm{NaHCO}_{3}$ was removed and added to $10 \mathrm{ml}$ scintillation fluid and counted in a $\beta$-counter with a dual label programme especially developed for ${ }^{3} \mathrm{H} /{ }^{14} \mathrm{C}$ counting. After counting, the individual blastocyst results were corrected for nonspecific activity (blank) and using the counts from the tubes containing total label present and a known concentration of substrate, the amounts of $\mathrm{CO}_{2}$ and $\mathrm{H}_{2} \mathrm{O}$ were calculated in pmols, and then divided by three to obtain a value of pmol per blastocyst $\mathrm{h}^{-1}$. The efficiency of recovery of the $\left[{ }^{14} \mathrm{C}\right] \mathrm{O}_{2}$ and $\left[{ }^{3} \mathrm{H}\right]_{2} \mathrm{O}$, from the incubation droplet to the trap was determined by incubating $241.5 \mathrm{ml}$ Eppendorf tubes used for embryo incubations with $5 \mathrm{ml}$ (for wallabies) of media containing the equivalent activity of $\left[{ }^{3} \mathrm{H}\right]_{2} \mathrm{O}$ and $\left[{ }^{14} \mathrm{C} \mathrm{O}_{2}\right.$ in the lid, and the $\mathrm{NaHCO}_{3}$ trap in the base as used for embryo incubations. The centrifuge tubes were incubated for up to $4 \mathrm{~h}$ at $37^{\circ} \mathrm{C}$, and three tubes were removed every $30 \mathrm{~min}$, and the trap was removed and added to scintillation fluid. These vials were counted on the dual-nucleotide programme and averaged to give a recovery efficiency over time. The recovery efficiencies for ${ }^{3} \mathrm{H}_{2} \mathrm{O}$ and ${ }^{14} \mathrm{CO}_{2}$ after incubation for $3 \mathrm{~h}$ were $100 \%$ and $99.2 \%$, respectively. Blastocyst data were corrected for rates of recovery efficiency before further analysis.

Uptake of glutamine and production of ammonium by individual blastocysts were determined by microfluorescence as described by Leese and Barton (1984). Micropipettes, constructed on a microforge, and calibrated using tritiated water (Mroz and Lechene, 1980), were used to remove samples from the droplets after incubation which were then added to one of two assay droplets, specifically linking either glutamine (Gardner et al., 1989) or ammonium (Gardner and Lane, 1993) to the oxidation or reduction of $\mathrm{NAD}(\mathrm{P}) \mathrm{H}$. Briefly, glutamine is a two part assay and requires glutamine to be converted to glutamate by adding 1 part sample to 4 parts glutamine reagent droplet $(50 \mathrm{U}$ glutaminase $\mathrm{ml}^{-1}(\mathrm{EC}$ 3.5.1.2), acetate buffer, $\mathrm{pH} 5.0) 1$ part of which is added to glutamate assay reagent droplets (1.6 mmol $\mathrm{NAD}^{+} \mathrm{ml}^{-1}, 1.0 \mathrm{mmol}$ ADP $\mathrm{l}^{-1}, 100 \mathrm{U}$ glutamate dehydrogenase $(\mathrm{GDH}) \mathrm{ml}^{-1}$ (EC 1.4.1.3), glycine hydrazine buffer, $\mathrm{pH}$ 9.4). The concentration of glutamine in the medium droplets was also assayed and subtracted from the values from the above assay to give total glutamine concentration. The ammonium assay is a single step procedure wherein 1 part sample was added to 10 parts ammonium reagent droplet $\left(14.15 \mathrm{mmol} \alpha\right.$-ketoglutarate $\mathrm{l}^{-1}$, $1.0 \mathrm{mmol} \mathrm{NADH} 1^{-1}, 0.629 \mathrm{mmol}$ ADP $\mathrm{l}^{-1}, 0.75 \mathrm{mmol}$ $\mathrm{NaHCO}_{3} \mathrm{l}^{-1}, 3 \mathrm{U}$ glutamate dehydrogenase (GDH) $\mathrm{ml}^{-1}(\mathrm{EC}$ 1.4.1.3), $157 \mathrm{mmol}$ triethanolamine buffer $\mathrm{l}^{-1}, \mathrm{pH}$ 8.0). The concentration of $\mathrm{NAD}(\mathrm{P}) \mathrm{H}$ in the reagent droplets before and after the addition of samples was determined by measuring the emitted fluorescence using a quantitative fluorescent microscope (Zeiss Axiovert). Concentrations of glutamine and ammonium in blastocyst and blank (control) incubation droplets were then determined using standard curves performed on each day of experimentation. The mean correlation coefficients for all standard curves for glutamine and ammonium were 0.996 and 0.989 , respectively. The amount of glutamine taken up and ammonium produced by blastocysts per hour were then determined. The rate of ATP production was calculated using the maximum ATP yield from each metabolic process. The complete oxidation of glutamine yields 33 ATP, while partial oxidation yields only 6 ATP, while palmitate oxidation yields 129 ATP. The total ATP production from glutamine used the assumption that the glutamine that was taken up by the blastocysts but not completely oxidized was probably at least partially oxidized and therefore used to produce 6 ATP. Thus ATP from glutamine was calculated as the amount oxidized multiplied by 33 , in addition to the amount of glutamine taken up but not oxidized multiplied by 6 , and ATP from palmitate was calculated as the amount of palmitate used multiplied by 129.

Blastocysts were then removed from incubation droplets, rinsed in PBS-BSA, and placed in $0.3 \mu$ l of somatic cell releasing reagent (SCRR; Sigma, Sydney), and the shell membrane (keratin-like tertiary investment surrounding trophoblast) and trophoblast punctured. Samples of this solution were then added to droplets ( 1 in 4 dilution) containing reagents that link ATP (reagents: $3.7 \mathrm{mmol}$ $\mathrm{MgSO}_{4} \cdot 7 \mathrm{H}_{2} \mathrm{O}^{-1}, 0.6 \mathrm{mmol} \mathrm{NADP}{ }^{+} \mathrm{l}^{-1}, 0.25 \mathrm{mmol}$ glucose $\mathrm{l}^{-1}$, $0.5 \mathrm{mmol}$ dithiothreitol $\mathrm{l}^{-1}, 20 \mathrm{U}$ hexokinase $\mathrm{ml}^{-1}$ (EC 2.7.1.1), 
$10 \mathrm{U}$ glucose-6-phosphate dehydrogenase (G6PDH) $\mathrm{ml}^{-1}$ (EC 1.1.1.49), EPPS buffer, $\mathrm{pH}$ 8.0) or ADP (reagents: 26 $\mathrm{mmol} \mathrm{MgSO}_{4} \cdot 7 \mathrm{H}_{2} \mathrm{O} \mathrm{l}^{-1}, 94 \mathrm{mmol} \mathrm{KCl} \mathrm{l}{ }^{-1}, 0.42 \mathrm{mmol} \mathrm{NADH}$ $\mathrm{l}^{-1}, 0.13 \mathrm{mmol}^{-2 T P} \mathrm{l}^{-1}, 0.65 \mathrm{mmol}$ dithiothreitol $\mathrm{l}^{-1}, 0.71 \mathrm{mmol}$ phosphoenolpyruvate $\mathrm{l}^{-1}, 20 \mathrm{U}$ lactate dehydrogenase (LDH) $\mathrm{ml}^{-1}$ (EC 1.1.1.27), $10 \mathrm{U}$ pyruvate kinase $\mathrm{ml}^{-1}$ (EC 2.7.1.40), EPPS buffer, $\mathrm{pH} 8.0$ ) with the reduction or oxidation of $\mathrm{NAD}(\mathrm{P}) \mathrm{H}$ (Leese et al., 1984). The mean correlation coefficients for all standard curves for ATP and ADP assays were 0.998 and 0.996, respectively. ATP and ADP concentrations (and therefore ATP:ADP ratio) of blastocyst and control samples were determined, as described above.

\section{Analysis of endometrial metabolism}

Small sections (about $1 \mathrm{~mm}^{3}$ ) of endometrium were dissected and rinsed through several drops of medium containing $1 \mathrm{mmol}$ glucose $\mathrm{1}^{-1}$ and finally rinsed in media containing $0.005 \mathrm{mmol}\left[{ }^{3} \mathrm{H}\right]-5$-glucose $1^{-1}$ and $0.995 \mathrm{mmol}$ unlabelled glucose $\mathbf{1}^{-1}$. The sections of endometrium were transferred individually to a $5 \mu \mathrm{l}$ drop of this media on the lid of a $1.5 \mathrm{ml}$ Eppendorf microcentrifuge tube. $1.5 \mathrm{ml}$ of $25 \mathrm{mmol} \mathrm{NaHCO} \mathrm{l}^{-1}$ was used as a trap for all evolved ${ }^{3} \mathrm{H}_{2} \mathrm{O}$. After incubation for $1 \mathrm{~h}$ at $37^{\circ} \mathrm{C}, 1 \mathrm{ml}$ of the trap was removed and added to vials containing $10 \mathrm{ml}$ scintillation fluid for counting to determine the activity of the Embden-Meyerhoff pathway of these cells. These vials were counted on a $\beta$-counter on a programme for detecting ${ }^{3} \mathrm{H}$ activity. Amount of $\left[{ }^{3} \mathrm{H}\right]$ glucose metabolized by endometrial tissue was then calculated as above. The metabolism data were standardized by using the Biorad Protein Assay (Biorad, Sydney) to determine the amount of protein in each section of tissue, as weight of the samples could not be measured accurately. Endometrial glucose metabolism ( $\mathrm{pmol}^{-1} \mathrm{mg}^{-1}$ protein $\mathrm{h}^{-1}$ ) was then used to determine the relative activity of blastocysts recovered at the same time after RPY.

\section{Analysis of mitotic rate and number of cells}

Immediately after recovery from the uterus, a separate group of blastocysts $(n=24)$ was recovered (days $0,3,4,5,6$ and 10 after RPY) rinsed several times in PBS supplemented with $2 \mathrm{mg} \mathrm{BSA} \mathrm{ml} \mathrm{m}^{-1}$, and placed in $10 \mathrm{ml}$ drops of PBS supplemented with $1 \mathrm{mmol}$ glucose and lactate $\mathrm{ml}^{-1}$, amino acids (MEM essential and non-essential) $2 \mathrm{mg} \mathrm{BSA} \mathrm{ml}^{-1}$ and $2 \mu \mathrm{g}$ colcemid $\mathrm{ml}^{-1}$, for $2 \mathrm{~h}$, and then fixed in Bodians solution (neutral buffered formalin:glacial acetic acid: $80 \%$ ethanol; $4: 1: 10$ ), and stored until analysis. Embryos were removed from the fixative and rinsed in PBS-BSA no more than 3 weeks after colcemid incubation and individually incubated in $0.5 \mathrm{ml}$ PBS-BSA with $10 \mu \mathrm{g}$ Hoechst $33342 \mathrm{ml}^{-1}$ for $20 \mathrm{~min}$. Blastocysts were removed and then left in PBS-BSA (for a maximum of $24 \mathrm{~h}$ ) until background staining reduced sufficiently to count number of cells and mitoses (Fig. 1). The average number of cells and mitoses $\mathrm{h}^{-1}$ (mitotic index) were then calculated.

\section{Statistical analysis}

All data were naturally log transformed to reduce inequality of variance (heteroscedasticity). Statistical outliers were identified by box-plot analysis, and removed from further analysis. Differences between and within days were subsequently analysed using analysis of variance. Differences between means were analysed using the Dunnett test for multiple pairwise comparisons (Miller, 1981).

\section{Results}

The average surface area of the blastocysts studied here did not differ significantly from that of day 0 blastocysts $(0.14 \pm$ $\left.0.02 \mathrm{~mm}^{2}\right)$ until 7 days after RPY $\left(0.49 \pm 0.06 \mathrm{~mm}^{2}\right)$ and increased further by day $10\left(3.62 \pm 1.25 \mathrm{~mm}^{2}\right)$. This pattern is similar to that reported by Spindler et al. (1995). Glutamine uptake and ammonium production by blastocysts were significantly greater on day 4 after RPY than on day 0 and had increased further by day 10 (Table 1). However, the rate of glutamine oxidation did not differ from blastocysts in diapause $\left(3.5 \pm 3.2\right.$ pmol per embryo $\left.h^{-1}\right)$ until day 10 after RPY $\left(22.0 \pm 4.5 \mathrm{pmol}\right.$ per embryo $\left.\mathrm{h}^{-1} ; \quad P<0.01\right)$. The percentage of glutamine taken up by blastocysts that was oxidized was significantly different from that of quiescent blastocysts $(4.5 \pm 3.1 \%)$ by day 5 after RPY $(31.2 \pm 12.6 \%$; $P<0.01)$, and increased to $51.0 \pm 15.8 \%(P<0.01)$ by day 10 after RPY (Table 1).

Table 1. Glutamine uptake, ammonium production, glutamine oxidation and percentage of glutamine oxidized by tammar blastocysts

\begin{tabular}{|c|c|c|c|c|}
\hline $\begin{array}{l}\text { Time (days } \\
\text { after RPY) }\end{array}$ & 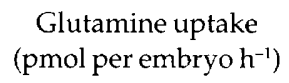 & 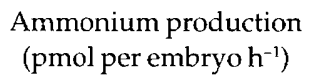 & $\begin{array}{l}\text { Glutamine oxidation } \\
\left(\mathrm{pmol}^{2} \text { per embryo } \mathrm{h}^{-1}\right)\end{array}$ & $\begin{array}{c}\text { Percentage of } \\
\text { glutamine oxidized }\end{array}$ \\
\hline 0 & $15.67 \pm 6.60$ & $8.24 \pm 4.32$ & $3.57 \pm 3.20$ & $4.58 \pm 3.15$ \\
\hline 3 & $22.41 \pm 8.94$ & $18.00 \pm 9.67$ & $0.68 \pm 0.08$ & $3.90 \pm 1.42$ \\
\hline 4 & $36.17 \pm 2.77^{* *}$ & $26.67 \pm 3.02^{* *}$ & $3.38 \pm 1.79$ & $8.74 \pm 0.41$ \\
\hline 5 & $33.82 \pm 8.01^{* *}$ & $23.86 \pm 7.41^{* *}$ & $5.63 \pm 0.86$ & $31.28 \pm 4.50^{* *}$ \\
\hline 10 & $52.91 \pm 7.43^{* *}$ & $53.26 \pm 11.53^{* *}$ & $22.05 \pm 4.50^{* *}$ & $51.05 \pm 15.86^{* *}$ \\
\hline
\end{tabular}

Asterisks denote that values are significantly different from blastocysts recovered during diapause and analysed simultaneously $\left({ }^{*} P<0.05 ;{ }^{*} P<0.01\right)$. RPY: removal of pouch young. 

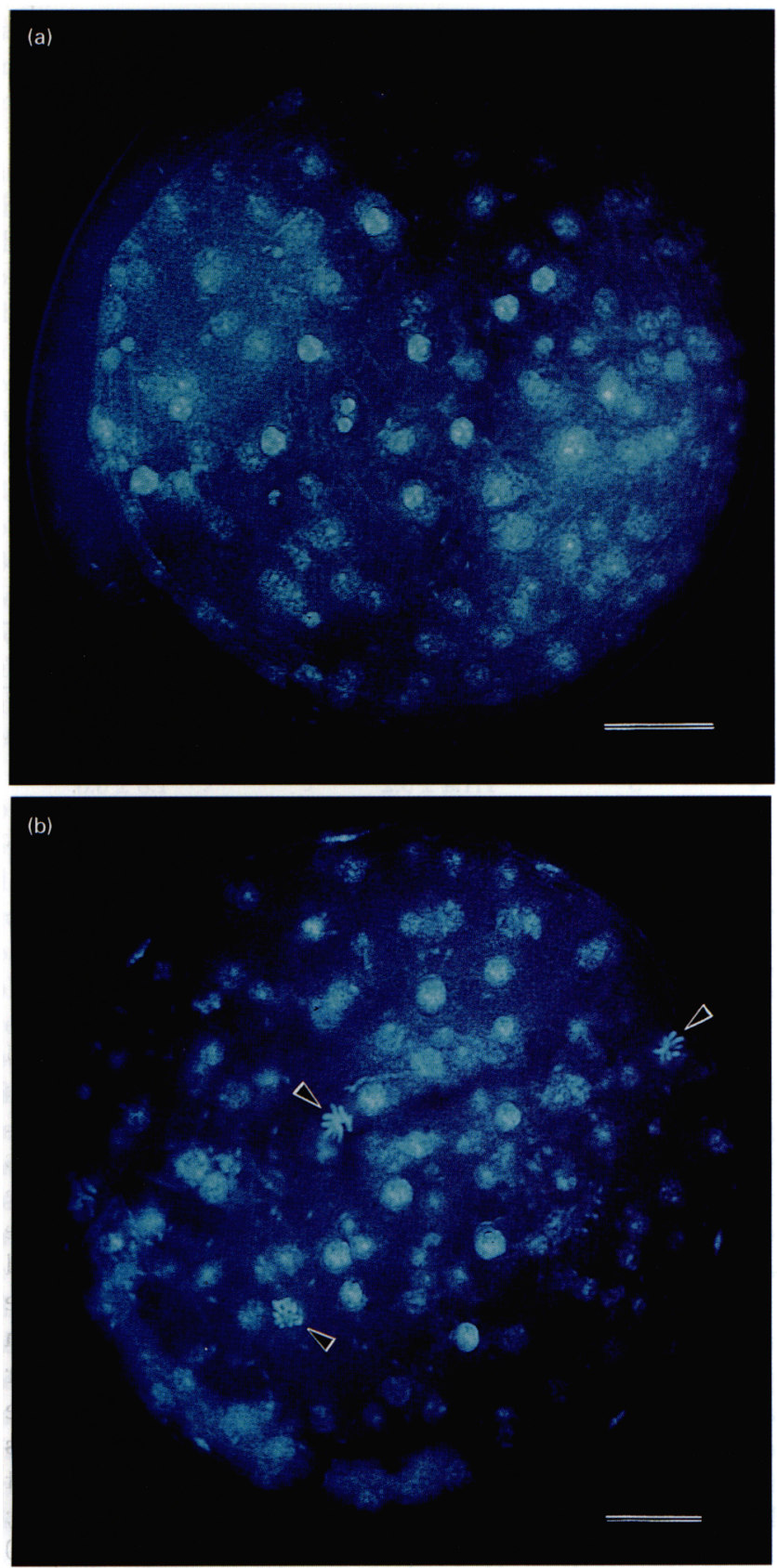

Fig. 1. No mitoses were observed in tammar blastocysts recovered on day 0 (a). They were first observed on day 4 and were frequently observed in blastocysts recovered on day 6 (b). Arrowheads indicate mitoses. Scale bars represent $20 \mu \mathrm{m}$.

Although palmitate oxidation by blastocysts recovered 4 days after RPY was variable (Fig. 2), blastocysts recovered on day 4 oxidized palmitate at a significantly greater rate than did day 0 blastocysts $(P<0.01)$ and blastocysts recovered on day 10 after RPY oxidized most palmitate (Fig. 2). The two blastocysts that metabolized more palmitate 4 days after RPY were not outliers, and therefore not removed from analysis. This variability of blastocysts at day 4 is consistent with the observed variation in endometrial metabolism. Endometrial

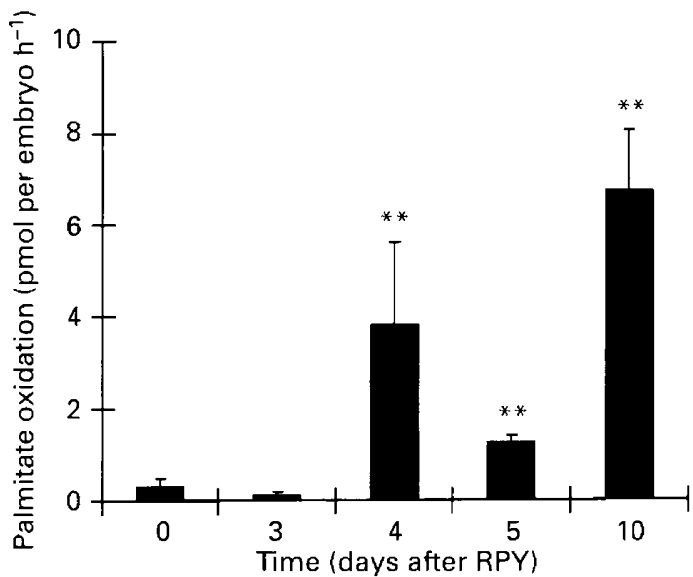

Fig. 2. Palmitate oxidation by reactivating tammar wallaby blastocysts. All values are means \pm SEM. Asterisks denote that values are significantly different from quiescent blastocysts measured simultaneously $(* * p<0.01)$

samples expressed a similar pattern of glucose metabolism as reported by Spindler $e t$ al. (1998), although the metabolism of endometrial samples recovered from animals 4 days after RPY is variable. The blastocysts recovered on day 4 that oxidized palmitate at a greater rate were recovered from females with highly active endometrium (47.00 and 46.88 nmol glucose $\mathrm{h}^{-1} \mathrm{mg}^{-1}$ protein), compared with other animals of the same stage $\left(12.47,8.41\right.$ and $6.20 \mathrm{nmol}$ glucose $\mathrm{h}^{-1} \mathrm{mg}^{-1}$ protein). The correlation between palmitic acid oxidation and endometrial metabolism was significant $\left(r^{2}=0.852 ; P<\right.$ 0.01 ).

Data on metabolism per cell are not available as determination of the number of cells was obtained from a separate batch of embryos. However, all parameters of metabolism per unit surface area increased steadily from day 0 (glutamine uptake: $107.14 \pm 5.32 \mathrm{pmol} \mathrm{mm}^{-2}$; ammonium production: $52.53 \pm 3.91 \mathrm{pmol} \mathrm{mm}^{-2}$; glutamine oxidation: $21.48 \pm 2.41 \mathrm{pmol} \mathrm{mm}^{-2}$; palmitate oxidation: $2.14 \pm 0.05$ pmol $\mathrm{mm}^{-2}$ to day 5 (glutamine uptake: $233.58 \pm 16.23 \mathrm{pmol}$ $\mathrm{mm}^{-2}$; ammonium production: $181.93 \pm 8.31 \mathrm{pmol} \mathrm{mm}^{-2}$; glutamine oxidation: $28.36 \pm 4.29 \mathrm{pmol} \mathrm{mm}^{-2}$; palmitate oxidation: $10.72 \pm 1.75 \mathrm{pmol} \mathrm{mm}^{-2}$ ) but decreased below that of day 0 blastocysts at day 10 (glutamine uptake: $13.99 \pm$ 1.67 pmols $\mathrm{mm}^{-2}$; ammonium production: $14.17 \pm 2.53$ pmols $\mathrm{mm}^{-2}$; glutamine oxidation: $5.85 \pm 0.96$ pmols $\mathrm{mm}^{-2}$; palmitate oxidation: $1.97 \pm 0.03$ pmols $\mathrm{mm}^{-2}$.

The ATP:ADP ratio within blastocysts was reduced by the first measurement at day $3(0.5 \pm 0.25)$ compared with day 0 blastocysts $(1.46 \pm 0.38)$, and remained low throughout the period studied (Fig. 3). The reduction in the ATP:ADP ratio was due to both reduced ATP (day 0: $0.94 \pm 0.18$ pmol per embryo; day 10: $0.11 \pm 0.02$ pmol per embryo) and increased $\operatorname{ADP}$ (day 0: $0.57 \pm 0.26$ pmol per embryo; day 10: $1.54 \pm 0.08$ pmol per embryo). The maximum rate of ATP production was calculated from the rate of uptake and oxidation of glutamine and the oxidation of palmitate and was significantly higher than in day 0 blastocysts by day 4 after RPY, and increased further by day 10 after RPY (Table 2). The increase in palmitate oxidation and the increase in glutamine 
Table 2. Maximum calculated ATP production from glutamine and palmitate metabolism by tammar wallaby blastocysts

\begin{tabular}{lcccc}
\hline $\begin{array}{l}\text { Time (days } \\
\text { after RPY) }\end{array}$ & $n$ & $\begin{array}{c}\text { ATP production } \\
\text { from glutamine } \\
\left(\text { pmol per embryo }^{-1}\right)\end{array}$ & $\begin{array}{c}\text { ATP production } \\
\text { from palmitate } \\
\left(\text { pmol per embryo }^{-1}\right)\end{array}$ & $\begin{array}{c}\text { Total ATP production } \\
\left(\text { pmol per embryo }^{-1}\right)\end{array}$ \\
\hline 0 & 4 & $110.5 \pm 55.2$ & $38.9 \pm 19.4$ & $149.4 \pm 74.7$ \\
3 & 5 & $148.5 \pm 74.2$ & $13.7 \pm 6.8$ & $162.3 \pm 81.1$ \\
4 & 5 & $310.8 \pm 155.4$ & $488.6 \pm 244.3^{* *}$ & $799.4 \pm 399.7^{* *}$ \\
5 & 6 & $350.0 \pm 125.0^{*}$ & $160.5 \pm 57.3^{* *}$ & $510.6 \pm 182.3^{* *}$ \\
10 & 4 & $912.5 \pm 325.8^{* *}$ & $867.3 \pm 309.7^{* *}$ & $1779.8 \pm 635.6^{* *}$ \\
\hline
\end{tabular}

Asterisks denote that values are significantly different from blastocysts recovered during diapause and analysed simultaneously $\left({ }^{*} P<0.05{ }^{* *} P<0.01\right)$. RPY: removal of pouch young.

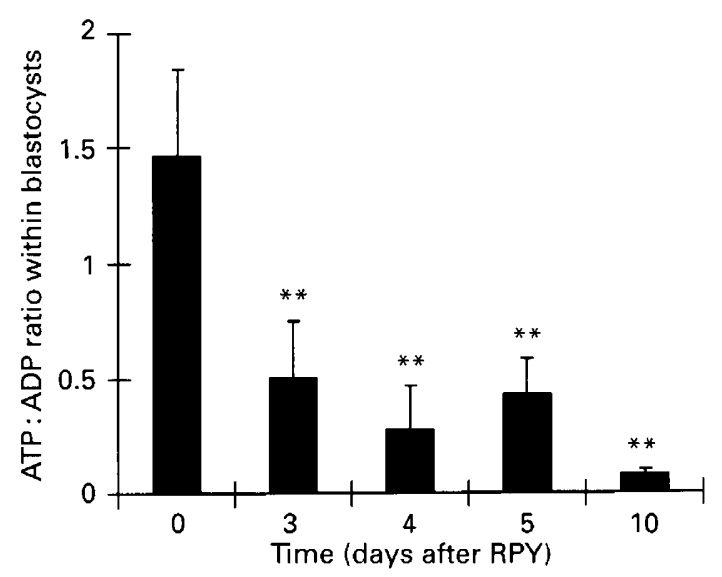

Fig. 3. The ATP:ADP ratio within tammar wallaby blastocysts. All values are means \pm SEM. Asterisks denote that values are significantly different from quiescent blastocysts measured simultaneously $\left({ }^{* *} P<0.01\right)$.

uptake by the blastocysts contribute equally to the calculated increase in ATP, although palmitate oxidation shows the greatest increase from quiescent values in the first 4 days after RPY.

Mitoses were first observed in three out of five blastocysts on day 4 after RPY. The number of mitoses increased each day until day 10, when nearly one quarter of the cells were dividing (Table 3). The number of cells in day 4 blastocysts was not significantly different from day 0 , but the number of cells increased at each interval examined thereafter until day 10 (Table 3).

\section{Discussion}

Tammar blastocysts recovered during the first 4 days of reactivation appear to oxidize a similar proportion of glutamine to that of lymphocytes (11\%; Newsholme et al., 1985) which are relatively inert in the absence of an immunological challenge. However, more glutamine is being oxidized by tammar blastocysts on day 5 after RPY and the percentage of glutamine oxidation continues to increase to over $50 \%$ by day 10 after RPY. Glutamine uptake was significantly higher than glutamine oxidation by tammar
Table 3. The number of cells and mitoses of wallaby blastocysts recovered on various days after RPY

\begin{tabular}{cccc}
\hline RPY & $n$ & Number of cells & Mitoses per embryo \\
\hline 0 & 7 & $100.7 \pm 4.2$ & 0 \\
3 & 5 & $103.0 \pm 3.5$ & 0 \\
4 & 5 & $111.4 \pm 5.2$ & $1.8 \pm 0.8^{* *}$ \\
5 & 4 & $124.7 \pm 3.0^{*}$ & $4.0 \pm 1.6^{* *}$ \\
6 & 5 & $145.2 \pm 14.1^{*}$ & $16.6 \pm 1.6^{* *}$ \\
10 & 5 & $459.8 \pm 33.1^{* *}$ & $91.4 \pm 13.9^{* *}$ \\
\hline
\end{tabular}

Asterisks denote that values are significantly different from blastocysts recovered during diapause and analysed simultaneously $\left({ }^{*} P<0.05\right.$; $\left.{ }^{* *} P<0.01\right)$. RPY: removal of pouch young.

blastocysts at all stages studied. Two of the major products of glutamine metabolism are ammonium and glutamate (Newsholme et al., 1985). Nearly all of the glutamine taken up by blastocysts recovered at all stages after RPY was deaminated to glutamate, as indicated by the high ammonium production from glutamine uptake.

Glutamine is an important precursor for structural molecules and genetic material essential for cell proliferation. Although the mitotic index was performed on a separate group of embryos, preventing any direct correlations between metabolism and mitotic rate of individual embryos, it is clear that mitoses of the tammar blastocyst have begun by day 4 after RPY, and continue to increase throughout the period studied. This process requires energy, which is reflected in an increase in the percentage of glutamine that was taken up and oxidized by day 5 blastocysts. It is possible that glutamine taken up during the period of resumed cell proliferation was used to provide biosynthetic precursors, and only oxidized during expansion of the blastocyst to supplement the energy supplied by other energy substrates such as glucose and palmitate. Similarly, glutamine uptake by cattle blastocysts increases during the period of blastocyst expansion, but glutamine metabolism does not increase until the blastocyst has hatched from the shell and begins extensive elongation (Rieger et al., 1992a). The metabolism per unit surface area increased to day 5 but actually decreased during expansion, indicating that metabolism of individual cells increased during the early stages of reactivation (days 4-5) but that later increases in embryo metabolism (day 10) were due to a 
larger number of cells which may actually be less active individually, but together produce sufficient energy for expansion of the blastocyst.

Palmitate oxidation increases during the period of initial activity of the blastocysts, but increases even further during the expansion phase. This finding supports the hypothesis that fatty acids, palmitate in particular, play a role in blastocyst expansion. It also supports previous evidence that the wallaby blastocyst undergoes metabolic reaction by day 4 after a decrease in the ATP:ADP ratio. Glutamine and palmitate are oxidized through the TCA cycle, so a high ATP:ADP ratio may block the oxidative metabolism of these substrates by regulating the enzymes pyruvate dehydrogenase, isocitrate dehydrogenase and 2oxoglutarate dehydrogenase (Newsholme and Leach, 1983; Stryer, 1995). The decreased ATP:ADP ratio during reactivation could alleviate this inhibition and allow the resumption of oxidative metabolism by the blastocyst. When energy requirements increase as mitotic division resumes at about day 4 after RPY, substrate flux through metabolic pathways increases, thus providing the energy required.

The variability in day 4 blastocysts has been observed previously (Thornber et al., 1981; Shaw and Renfree, 1986; Spindler et al., 1998), and suggests that this may be the first day that discernible changes in maternal and blastocyst activity are detected. This coincident variability in blastocyst palmitate oxidation and endometrial metabolism by day 4 blastocysts probably reflects accelerated reactivation of certain females whose pouch young were removed 4 days before as described by Spindler et al. (1998). This finding indicates that these females, and therefore the blastocysts reached a more advanced stage of reactivation than other animals of the same 'age' and supports the suggestion that variation in blastocyst activity is intrinsically linked to and initiated by maternal reactivation and cannot be predicted purely by the number of days after RPY (Spindler et al., 1998). Even though an increase in endometrial activity of the remaining day 4 wallabies was not detected, the resumption of mitoses in day 4 blastocysts suggests that the blastocyst has already received some signal from the maternal environment to begin the next phase of rapid growth.

Blastocyst oxidation of glutamine and palmitate is less than that of glucose (Spindler et al., 1995); however, the levels of use are significant, possibly due to greater availability of amino and fatty acids in the uterine environment. In addition, the relatively large amounts of ATP produced from the complete oxidation ( $33 \mathrm{pmol}$ ATP) and partial oxidation (6 ATP) of each pmol of glutamine and the oxidation of palmitate (129 pmol ATP) allow great energy production from small amounts of substrate. The calculated total ATP production from these two substrates is similar to that produced from glucose by tammar blastocysts recovered at day $4\left(612.0 \pm 117.7\right.$ pmol per embryo $\left.h^{-1}\right)$, but significantly lower than ATP production from glucose by day 10 blastocysts ( $6401.2 \pm 2987.4 \mathrm{pmol}$ per embryo $\mathrm{h}^{-1}$; Spindler $e t$ al., 1998). Blastocysts are therefore likely to use fatty acids and amino acids or other energy substrates to supplement glucose metabolism when energy expenditure is high.

Examining individual substrates gives valuable information on the ability of embryos to use that substrate.
However, studies examining the additive effects of several energy sources are essential to understand fully the mechanisms controlling embryo metabolism and subsequent development. Wallaby blastocysts appear to have a high oxidative capacity in that they are capable of oxidizing glutamine and palmitate as well as glucose; however, it is not known to what extent these substrates are available to the embryo in utero. Embryo metabolism is known to be plastic and the metabolism displayed here may reflect only a capacity rather than requirement for these substrates. For example the ratios of fatty acids presented to rabbit zygotes appear more important than the presence of any single fatty acid (Waterman and Wall, 1988). Therefore, studies are now required to determine the extent of competition or synergy between these and other substrates, particularly during expansion of the blastocoel, to determine the biological importance of each substrate, or group of substrates to the embryo.

The authors thank Don Rieger for helpful discussions on the energetics of blastocyst expansion, and the pathways of glutamine metabolism.

\section{References}

Annison EF and Armstrong DG (1970) Volatile fatty acid metabolism and energy supply. In Physiology of Digestion and Metabolism in the Ruminant pp 422-437 Ed. AT Phillipson. Oriel Press, Newcastle

Bavister BD and McKiernan SH (1993) Regulation of hamster embryo development in vitro by amino acids. In Preimplantation Embryo Development pp 57-72 Ed. BD Bavister. Plenum Press, New York

Berger PJ (1970) Reproductive Biology of the Tammar Wallaby Macropus eugenii. PhD Thesis Tulane University Dissertation Abstracts International 31B 3760-3761

Benos DJ and Balaban RS (1980) Energy requirements of the developing mammalian blastocyst for active ion transport Biology of Reproduction 23 941-947

Betteridge KJ, Eaglesome MD and Randall GCB (1980) Collection description and transfer of embryos from cattle 10-16 days after oestrus Journal of Reproduction and Fertility 59 205-216

Bierman EL, Schwartz IL and Dole VP (1957) Action of insulin on release of fatty acids from tissue stores American Joumal of Physiology 191 359-362

Biggers JD and Stern S (1973) Metabolism of the preimplantation mammalian embryo Advances in Reproductive Technology $61-60$

Biggers JD, Lawitts JA and Lechene CP (1993) The protective action of betaine on the deleterious effects of $\mathrm{NaCl}$ on preimplantation mouse embryos in vitro. Molecular Reproduction and Development 34 380-390

Brown GD (1959) The Nitrogen Requirement of the Euro, Macropus robustus. BSc, University of Western Australia

Carney EW and Bavister BD (1987) Stimulatory and inhibitory effects of amino acids on the development of hamster eight cell embryos in vitro. Journal of In Vitro Ferfilisation and Embryo Transfer 4 162-167

Chatot CL, Ziomek CA, Bavister BD, Lewis JL and Torres I (1989) An improved culture medium supports development of random bred 1-cell mouse embryos in vitro. Journal of Reproduction and Fertility $86679-688$

Chatot CL, Tasca RJ and Ziomek CA (1990) Glutamine uptake and utilisation by preimplantation mouse embryos in CZB medium Journal of Reproduction and Fertility $89335-346$

Deighton N and Hider RC (1989) Intercellular low molecular weight iron Biochemical Society Transactions 17490

Du ZF and Wales RG (1993) Effect of culture from the zygote stage on the metabolism of glucose and glutamine by 2-cell embryos and blastocysts recovered from outbred or F1 hybrid female mice Reproduction, Fertility and Development 5 555-565

Fletcher TP, Jetton AE and Renfree MB (1988) Influence of progesterone and oestradiol-17 $\beta$ on blastocysts of the tammar wallaby (Macropus engenii) during seasonal diapause Journal of Reproduction and Fertility 76 339-347 
Flynn TJ and Hillman N (1980) The metabolism of exogenous fatty acids by preimplantation mouse embryos developing in vitro. Journal of Embryology and Experimental Morphology 56 157-168

Fredrickson DS and Gordon RS (1958) Transport of fatty acids Physiology Reviezo $38585-630$

Fridhandler L (1961) Pathways of glucose metabolism in fertilised rabbit ova at various preimplantation stages Experimental Cell Research 222 303-316

Gardner DK and Lane M (1993) Amino acids and ammonium regulate mouse embryo development in culture Biology of Reproduction 48 377-385

Gardner DK, Clarke RN, Lechene CP and Biggers JD (1989) Development of a non-invasive ultramicrofluorometric method for measuring net uptake of glutamine by single preimplantation mouse embryos Gamete Research 24 $427-438$

Gardner DK, Lane M and Batt P (1993) Uptake and metabolism of pyruvate and glucose by individual sheep preattachment embryos developed in vivo. Molecular Reproduction and Development 36 313-319

Gordon K, Fletcher TP and Renfree MB (1988) Reactivation of the quiescent corpus luteum and diapausing embryos after temporary removal of the sucking stimulus in the tammar wallaby (Macropus eugenii) Journal of Reproduction and Fertility 83 401-406

Hewitson LC (1993) Energy Metabolism of the Trophectoderm and Inner Cell Mass of the Mouse Blastocyst PhD Thesis, University of York

Hewitson LC, Martin KI, and Leese HJ (1996) Effects of metabolic inhibitors on mouse preimplantation embryo development and the energy metabolism of isolated inner cell masses Molecular Reproduction and Development 43 323-330

Homa ST, Racowsky C and McGaughey RW (1986) Lipid analysis of immature pig oocytes Joumal of Reproduction and Fertility 77 425-434

Home E (1814) Lectures on Comparative Anatomy Bulmer, London

Hume ID (1982) Digestive Physiology and Nutrition of Marsupiais Cambridge University Press, Cambridge

Jamshidi MB and Kaye PL (1995) Glutamine transport by mouse inner cell masses lournal of Reproduction and Fertility 104 91-97

Kane M (1979) Fatty acids as energy sources for culture of one-cell rabbit ova to viable morulae Biology of Reproduction 20 323-332

Kinnear JE and Main AR (1975) The recycling of urea nitrogen by the wild tammar wallaby (Macropus eugenii) - a 'ruminant-like' physiology Comparative Biochemistry and Physiology 51A 793-810

Lawitts JA and Biggers JD (1992) Joint effects of sodium chloride, glutamine and glucose in mouse preimplantation embryo culture media Molecular Reproduction and Development 31 189-194

Leese HJ and Barton AM (1984) Pyruvate and glucose uptake by mouse ova and preimplantation embryos Journal of Reproduction and Fertility 72 9-13

Leese HJ, Biggers JD, Mroz EA and Lechene C (1984) Nucleotides in a single mammalian ovum or preimplantation embryo Analytical Biochemistry 140 $443-448$

Lewis A and Kaye PL (1992) Characterisation of glutamine uptake in mouse twocell embryos and blastocysts Journal of Reproduction and Fertility 95 221-229

McKiernan SH, Bavister BD and Tasca RJ (1991) Energy substrate requirements for in vitro development of hamster 1- and 2-cell embryos to the blastocyst stage Human Reproduction 6 64-75

Menezo Y, Renard J-P, Delobel B and Pageaux J-F (1982) Kinetic study of fatty acid composition of day 7 to 14 cow embryos Biology of Reproduction 26 $787-790$

Miller RG (1981) Simultaneous Statistical Inference Springer-Verlag, New York

Moir RJ, Somers M and Waring $\mathbf{H}$ (1956) Studies on marsupial nutrition Australian Journal of Biological Sciences $9293-304$

Mroz EA and Lechene C (1980) Fluorescence analysis of picolitre samples Analytical Biochemistry 102 90-96

Newsholme EA and Leech AR (1983) Biochemistry for the Medical Sciences John Wiley and Sons, London

Newsholme EA, Crabtree B and Ardaw MSM (1985) Glutamine metabolism in lymphocytes: its biochemical, physiological and clinical importance Quarterly Journal of Experimtental Physiology $70473-489$

Nonogaki T, Noda Y, Goto Y, Kishi J and Mori T (1994) Developmental blockage of mouse embryos caused by fatty acids Journal of Assisted Reproduction and Genetics $11482-488$
Owen $\mathbf{R}$ (1834) Notes on the anatomy of a new species of kangaroo Macropus parryi Benn Proceedings of the Zoological Society of London

Petters RM, Johnson BH, Reed ML and Archibong AE (1990) Glucose, glutamine and inorganic phosphate in early development of the pig embryo in vitro. Journal of Reproduction and Fertitity $89269-275$

Pike IL (1981) Comparative studies of embryo metabolism in early pregnancy Journal of Reproduction and Development Supplement 29 203-213

Quinn P and Whittingham DC (1982) Effect of fatty acids on fertilisation and development of mouse embryo in vitro. Journal of Andrology 3440-444

Renfree MB (1970) Protein amino acids and glucose in the yolk-sac fluids and maternal blood sera of the tammar wallaby Macropus eugenii (Desmarest) lournal of Reproduction and Fertility 22 483-492

Renfree MB (1973) The composition of fetal fluids of the marsupial Macropus eugenii. Developmental Biology 33 62-79

Renfree MB and Calaby JH (1981) Background to delayed implantation and embryonic diapause Journal of Reproduction and Fertility Supplenent 29 1-9

Rieger D (1992) Relationships between energy metabolism and development of early mammalian embryos Theriogenology 37 75-93

Rieger D and Guay P (1988) Measurement of metabolism of energy substrates in individual bovine blastocysts Journal of Reproduction and Fertility 83 585-591

Rieger D, Lagneau-Petit D and Palmer E (1987) Preliminary investigations of the metabolic activity of early horse embryos journal of Reproduction and Fertility 35 699-700

Rieger D, Loskutoff NM and Betteridge KJ (1992a) Developmentally related changes in the uptake and metabolism of glucose, glutamine and pyruvate by cattle embryos produced in vitro. Reproduction, Fortility and Development 4 547-557

Rieger D, Loskutoff NM and Betteridge KJ (1992b) Developmentally related changes in the metabolism of glucose and glutamine by cattle embryos produced and co-cultured in vitro. Journal of Reproduction and Fertility 95 585-595

Shaw G and Renfree MB (1986) Uterine and embryonic metabolism after diapause in the tammar wallaby Macropus eugenii. Journal of Reproduction and Fertility 76 339-347

Spindler RE, Renfree MB, Shaw G and Gardner DK (1995) Glucose metabolism by tammar wallaby blastocysts during embryonic diapause and reactivation Proceedings of the Australian Society of Reproductive Biology 27 42

Spindler RE, Renfree MB, Shaw G and Gardner DK (1998) Reactivating tammar wallaby blastocysts oxidize glucose Biology of Reproduction $\mathbf{5 8}$ $1425-1431$

Stryer L (1995) Biochemistry WH Freeman and Company, New York

Thompson JGE, Simpson AC, Pugh PA, Wright RW and Tervit HR (1991) Glucose utilisation by sheep embryos derived in vivo and in vitro. Reproduction, Fertility and Development 3 571-576

Thornber EJ, Renfree MB and Wallace GI (1981) Biochemical studies of intrauterine components of the tammar wallaby Macropus eugenit during pregnancy journal of Embryology and Experimental Morphology 62 325-338

Tiffin GJ, Rieger D, Betteridge KJ, Yadav BR and King WA (1991) Glucose and glutamine metabolism in preattachment cattle embryos in relation to sex and stage of development Reproduction, Fertility and Development 93 125-132

Tyndale-Biscoe $\mathrm{CH}$ and Renfree MB (1987) Reproductive Physiology of Marsupials Cambridge University Press, Cambridge

Wales RG and Du ZF (1994) The metabolism of glutamine by the preimplantation sheep conceptus and its interaction with glucose Reproduction. Fertility and Development 6 659-667

Waring H, Moir RJ and Tyndale-Biscoe CH (1966) Comparative physiology of marsupials Advances in Comparative Physiology and Biochemistry 2 237-376

Waterman RA and Wall RJ (1988) Lipid interactions with in vitro development of mammalian zygotes Gamete Research 21 243-254

Waugh EE and Wales RG (1993) Oxidative utilisation of glucose, acetate and lactate by early preimplantation sheep, mouse and cattle embryos Reproduction, Fertility and Development 5 123-133 